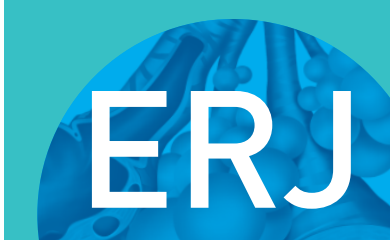

open research

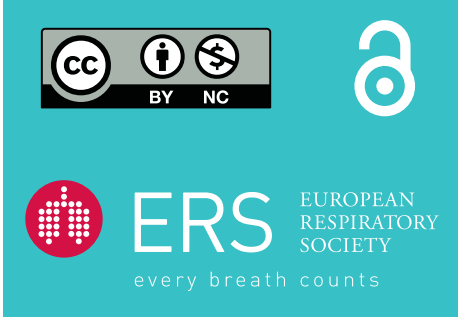

\section{Recruitment in online research for COPD: leveraging social media and research registries}

\author{
To the Editor:
}

An international priority is to engage patients at-risk of or living with chronic obstructive pulmonary disease (COPD) in online research and self-management programmes to establish evidence for their efficacy and obtain patient perspectives about healthcare [1]. Participatory social media and electronic research registries pose opportunities for stakeholders to readily access this patient population [2-4]. Despite increased access, patients with COPD continue to report limited willingness to participate in online disease-specific programmes and studies [5]. Recruitment is a science; it is a systematic and strategic process that is dependent on the values and needs of an intended audience. Identifying recruitment strategies, including message design, modality and timing, that are salient to an audience is critical to this process [6]. Social media and research registries are networks to reach patients with COPD for research and practice [7]; however, strategies to optimise their use for recruitment are less well known.

Combined use of online and offline methods alongside reminder notifications is recommended to optimise enrolment [8]. Pre-notifications inform individuals about an upcoming study, cognitively preparing them for the formal invitation and the opportunity make an informed decision about participation [9]. Pre-notification messages enhance enrolment rates in health survey research among adults over the age of 45 years [10]; however, inconsistent evidence exists for the efficacy of survey pre-notifications delivered by mail or email $[11,12]$. Despite widespread adoption of the Internet, patients with COPD are older and experience sporadic negative health events that influence their frequency of using online media to access recruitment messages [13]. Examining the efficacy of online and offline pre-notification messages that are salient to the priority audience is crucial to identify effective recruitment procedures.

In this report, we provide evidence for the efficacy of social media and research registry recruitment procedures for online COPD survey research. We examined if enrolment rates to an online survey differ across these two networks. We also examined how personalised pre-notifications co-created by patients and delivered to research registry members, by email or mail, can influence enrolment rates. Special attention was paid to examining enrolment differences by socio-geo-demographics and the degree of respiratory symptom severity. Ethical approval for all study procedures were approved by the lead researchers' Institutional Review Board at the University of Florida in Gainesville, FL, USA.

Upon completing an informed consent form, 10 patients with COPD belonging to a community-engaged research programme co-created the recruitment message with the lead researcher. Informants were mean \pm SD $64.40 \pm 16.35$ years old, Caucasian $(60 \%)$ or African American (40\%), and college educated $(60 \%)$ but earning USD 20000 per year or less (80\%). The message was initially drafted by the lead researcher and independently revised and edited by these informants through an iterative process. The procedure was guided by principles of message design in health research recruitment [14], which include elements of completeness (i.e. is the study purpose and participation process clear?), relevance (i.e. does the message draw your attention?) and credibility (i.e. is the message source perceived as trustworthy and of high quality?).

@ERSpublications

Social media and research registries effectively reach diverse subgroups of patients with obstructive lung conditions. Patient co-created mail and e-mail pre-notifications that precede a formal e-mail invitation can enhance enrolment in online research. http://ow.ly/gQQt30o6 $\mathrm{Bcw}$

Cite this article as: Paige SR, Krieger JL. Recruitment in online research for COPD: leveraging social media and research registries. ERJ Open Res 2019; 5: 00167-2018 [https://doi.org/10.1183/ 23120541.00167-2018].

Copyright ( $\mathrm{ERS}$ 2019. This article is open access and distributed under the terms of the Creative Commons Attribution Non-Commercial Licence 4.0 . 
TABLE 1 Characteristics of recruitment networks and research registry pre-notification groups

\begin{tabular}{|c|c|c|c|c|c|}
\hline & \multicolumn{2}{|c|}{ Recruitment networks } & \multicolumn{3}{|c|}{$\begin{array}{l}\text { Research registry pre-notification } \\
\text { cohorts }^{\S}\end{array}$} \\
\hline & $\begin{array}{l}\text { Social } \\
\text { media }\end{array}$ & $\begin{array}{l}\text { Research } \\
\text { registry }\end{array}$ & Mail & E-mail & Control \\
\hline Subjects $\mathrm{n}$ & 292 & 283 & 120 & 100 & 63 \\
\hline Mean士sD age years & $47.05 \pm 8.66$ & $63.50 \pm 10.44^{* * *}$ & $63.03 \pm 10.42$ & $64.02 \pm 10.14$ & $63.56 \pm 3.14$ \\
\hline Mean \pm sD rural identity ${ }^{\#}$ & $2.77 \pm 0.97$ & $3.27 \pm 1.40^{* * *}$ & $3.47 \pm 1.35$ & $3.11 \pm 1.43$ & $3.14 \pm 1.40$ \\
\hline Mean \pm sD rural residence ${ }^{\#}$ & $2.63 \pm 1.07$ & $3.36 \pm 1.39 * * *$ & $3.49 \pm 1.33$ & $3.20 \pm 1.45$ & $3.34 \pm 1.41$ \\
\hline $\begin{array}{l}\text { Mean士so respiratory } \\
\text { symptoms }\end{array}$ & $3.16 \pm 0.77 * * *$ & $2.44 \pm 0.99$ & $2.44 \pm 1.02$ & $2.46 \pm 0.98$ & $2.43 \pm 1.01$ \\
\hline \multicolumn{6}{|l|}{ Gender } \\
\hline Male & $178(61)$ & $120(42.4)$ & $56(46.7)$ & $41(41)$ & $23(36.5)$ \\
\hline Female & 96 (32.9) & $160(56.5)^{* * *}$ & 64 (53.3) & 59 (59) & $37(58.7)$ \\
\hline Prefer to not answer & $18(6.2)$ & $3(1.1)$ & $0(0)$ & $0(0)$ & $3(4.8)$ \\
\hline \multicolumn{6}{|l|}{ Race } \\
\hline White & $219(75)$ & $255(90.1)$ & 109 (90.8) & $89(89)$ & $57(90.5)$ \\
\hline Black/African American & $45(15.4)^{* * *}$ & $9(3.2)$ & 4 (3.3) & 3 (3) & $2(3.2)$ \\
\hline Asian American & $6(2.1)$ & $6(2.1)$ & $2(1.7)$ & $4(4)$ & $0(0)$ \\
\hline Native American & $10(3.4)$ & $3(1.1)$ & $2(1.7)$ & $1(1)$ & $0(0)$ \\
\hline Other & $10(3.4)$ & 9 (3.2) & $3(2.5)$ & 3 (3) & $3(4.8)$ \\
\hline Prefer to not answer & $2(0.7)$ & $1(0.4)$ & $0(0)$ & $0(0)$ & $1(1.6)$ \\
\hline \multicolumn{6}{|l|}{ Ethnicity } \\
\hline Hispanic & $100(34.2)^{* * *}$ & $8(2.8)$ & $2(1.7)$ & $6(6)^{* * *}$ & $0(0)$ \\
\hline Non-Hispanic & $191(65.4)$ & 242 (85.5) & 118 (98.3) & $74(74)$ & $50(79.4)$ \\
\hline Prefer to not answer & $1(0.3)$ & 33 (11.7) & $0(0)$ & $20(20)$ & $13(20.6)$ \\
\hline \multicolumn{6}{|l|}{ Education } \\
\hline Less than high school & $25(8.5)$ & 12 (4.3) & $2(1.6)$ & $8(8)$ & $2(3.2)$ \\
\hline High school or equivalent & 30 (10.3) & $36(12.7)$ & 16 (13.3) & $9(9)$ & $11(17.5)$ \\
\hline College experience & 235 (80.5) & 233 (82.3) & $101(84.1)$ & $83(83)$ & $49(78.1)$ \\
\hline Prefer to not answer & 2 (0.7) & $2(0.7)$ & $1(0.8)$ & $0(0)$ & $1(1.6)$ \\
\hline \multicolumn{6}{|l|}{ Income USD } \\
\hline$<24999$ & $10(3.4)$ & $60(21.2)^{* * *}$ & $20(16.7)$ & $24(24)$ & $16(25.4)$ \\
\hline $25000-34999$ & 30 (10.3) & $30(10.6)$ & $13(10.8)$ & $12(12)$ & $5(7.9)$ \\
\hline $35000-49999$ & 95 (32.5) & $29(10.2)$ & $14(11.7)$ & $9(9)$ & $6(9.5)$ \\
\hline $50000-74999$ & 91 (31.2) & $56(19.8)$ & $26(21.7)$ & $20(20)$ & 10 (15.9) \\
\hline$\geqslant 75000$ & $66(22.6)$ & $90(31.8)$ & $35(29.2)$ & 33 (33) & $22(34.9)$ \\
\hline Prefer to not answer & $0(0)$ & $18(6.4)$ & $12(10)$ & $2(2)$ & $4(6.3)$ \\
\hline \multicolumn{6}{|l|}{ Employment status } \\
\hline Full-time & $221(75.7)$ & 55 (19.4) & $24(20)$ & $18(18)$ & $13(20.6)$ \\
\hline Part-time & $29(9.9)$ & $12(4.2)$ & $6(5)$ & 3 (3) & $3(4.8)$ \\
\hline Unemployed & $7(2.4)$ & $8(2.8)$ & $5(4.2)$ & $1(1)$ & $2(3.2)$ \\
\hline Retired & $20(6.8)$ & $126(44.5)^{* * *}$ & $59(49.2)$ & 39 (39) & $28(44.4)$ \\
\hline Disabled & $9(3.1)$ & $70(24.7)$ & 23 (19.2) & $34(34)$ & $13(20.6)$ \\
\hline Other & $3(1.0)$ & $8(2.8)$ & $3(2.5)$ & $3(3)$ & $2(3.2)$ \\
\hline Prefer to not answer & $3(1.0)$ & $4(1.4)$ & $0(0)$ & $2(2)$ & $2(3.2)$ \\
\hline \multicolumn{6}{|l|}{ Marital status } \\
\hline Married & $234(80.1)^{* * *}$ & 161 (57.3) & 75 (62.5) & $56(56)$ & $30(47.6)$ \\
\hline Divorced & $24(8.2)$ & 64 (22.8) & 27 (22.5) & $21(21)$ & $16(25.4)$ \\
\hline Widowed & $11(3.8)$ & $32(11.4)$ & $11(9.2)$ & $13(13)$ & 8 (12.7) \\
\hline Separated & $11(3.8)$ & $6(2.1)$ & $1(0.8)$ & 2 (2) & $3(4.8)$ \\
\hline Single, never married & $11(3.8)$ & $18(6.4)$ & $5(4.2)$ & $8(8)$ & $5(7.9)$ \\
\hline Prefer to not answer & $1(0.3)$ & $2(0.7)$ & $1(0.8)$ & $0(0)$ & $1(1.6)$ \\
\hline \multicolumn{6}{|l|}{ Health insurance status } \\
\hline Insured & 246 (84.2) & $266(94.7)^{* *}$ & 115 (96.7) & $91(91)$ & 59 (93.7) \\
\hline Uninsured & $32(11)$ & $13(4.6)$ & 4 (3.3) & $6(6)$ & $3(4.8)$ \\
\hline Not sure & $10(3.4)$ & $2(0.7)$ & $0(0)$ & $2(2)$ & $0(0)$ \\
\hline Prefer to not answer & $4(1.4)$ & $2(0.7)$ & $0(0)$ & $1(1)$ & $1(1.6)$ \\
\hline \multicolumn{6}{|l|}{ Chronic disease $^{+}$} \\
\hline COPD & $264(90.4)^{* * *}$ & $143(50.5)$ & $59(49.2)$ & $57(57)$ & $27(57.1)$ \\
\hline Heart disease & $22(7.5)$ & $70(24.7) * * *$ & 23 (19.2) & $30(30)$ & 17 (27) \\
\hline Cancer & $15(5.1)$ & $49(17.3)^{* * *}$ & $17(14.2)$ & $22(22)$ & $10(15.9)$ \\
\hline
\end{tabular}




\begin{tabular}{|c|c|c|c|c|c|}
\hline & \multicolumn{2}{|c|}{ Recruitment networks } & \multicolumn{3}{|c|}{$\begin{array}{l}\text { Research registry pre-notification } \\
\text { cohorts }^{\S}\end{array}$} \\
\hline & $\begin{array}{l}\text { Social } \\
\text { media }\end{array}$ & $\begin{array}{l}\text { Research } \\
\text { registry }\end{array}$ & Mail & E-mail & Control \\
\hline Type 2 diabetes & $29(9.9)$ & $54(19.1)^{* *}$ & 22 (18.3) & $22(22)$ & 10 (15.9) \\
\hline Arthritis & $14(4.8)$ & $104(40.6)^{* * *}$ & 33 (35.5) & $46(46)$ & 25 (39.7) \\
\hline Chronic pain & $20(6.8)$ & $101(35.7)^{* * *}$ & 41 (34.2) & 37 (37) & $23(36.5)$ \\
\hline Other & $8(2.7)$ & $27(9.5)^{* *}$ & 13 (10.8) & $7(7)$ & $7(11.1)$ \\
\hline \multicolumn{6}{|c|}{$\begin{array}{l}\text { Data are presented as } n(\%) \text {, unless otherwise stated. COPD: chronic obstructive pulmonary disease. } \\
{ }^{\#} \text { : rural identity and region were measured on a five-point scale, } 1=\text { urban (city) and } 5=\text { rural (small town); } \\
{ }^{\uparrow} \text { : respiratory symptoms were measured on a five-point scale, } 1=\text { low and } 5=\text { high; }{ }^{+}: \text {chronic disease } \\
\text { percentages exceed } 100 \% \text {, given that participants could report multiple chronic conditions; }{ }^{\S} \text { : mailer } \\
\text { pre-notification } 17.14 \% \text { response rate, e-mail pre-notification } 14.29 \% \text { response rate, control } 9 \% \text { response } \\
\text { rate. }{ }^{* *}: p<0.01 ;{ }^{* * *}: p<0.001 \text {. }\end{array}$} \\
\hline
\end{tabular}

Participants were recruited for 1 week in April 2018. The 20-min survey included an electronic informed consent, followed by sociodemographics, including age and self-reported rurality ( $1=$ urban; $5=$ rural), and measures to assess COPD-related information seeking experiences, attitudes and beliefs. The presence of four respiratory symptoms (dyspnoea, cough, chest congestion and fatigue) was also measured (1=strongly disagree; 5=strongly agree) [15]

A National Institutes of Health-funded university-based research registry was used to identify 2100 eligible patients who were assigned a J40-J47 (minus J45) ICD-10 (International Classification of Diseases 10th Revision) code in their electronic health record, were at least 40 years old and had an email address on file. An equal number of participants were randomly assigned to one of three pre-notification groups: 1) an email message $(\mathrm{n}=700) ; 2)$ a United States Postal Service (USPS) mail letter with survey link ( $\mathrm{n}=700)$; and 3) control $(n=700)$. Email "bounce-backs" were reassigned to a pre-notification group using random simple sample procedures. Pre-notifications were delivered 3 days before the official email invitation. Reminder emails were delivered 3 days and 1 week after the official invitation. Among those invited, 436 (20.76\%) attempted the survey. Of those who attempted, 283 (64.91\%) completed at least half the survey.

The recruitment message and survey link were posted on a research listing webpage hosted by a university medical research centre. Language from the co-created pre-notification message was echoed in the social media content. Unsolicited public users shared the webpage on Facebook COPD groups. Of the 332 who attempted the survey, $292(88.25 \%)$ completed half of the survey items in consideration for subsequent analyses.

Table 1 presents the sociodemographic characteristics of 575 participants recruited through social media and the research registry. Chi-squared analyses were computed to detect statistically significant $(\mathrm{p}<0.05)$ differences between social media and registry respondents. Compared with the social media group, research registry participants were more likely to be older females with less severe respiratory symptoms who identified with rural culture and reside in a rural region. Research registry participants were also retired, earning USD 0-24999 per year, with health insurance and a history of marriage. Sociodemographics were nearly balanced across research registry pre-notification groups. Participants who received a pre-notification message were more likely to complete the survey than participants who did not receive a pre-notification $\left(77.7 \%\right.$ and $22.3 \%$, respectively), $\chi^{2}(1, n=283)=283, p<0.001$. In regard to the type of pre-notification, USPS mail pre-notifications were superior to email pre-notifications $(65.6 \%$ and $61.3 \%$, respectively), $\chi^{2}(1, \mathrm{n}=283)=113.85, \mathrm{p}<0.001$.

A research registry and social media research listing were equally effective in recruiting adults at-risk of or living with chronic obstructive lung conditions to a 20 -min online survey. Social media, however, was more effective in recruiting Black/African American and Hispanic patients. Pre-notifications increased enrolment of participants in the research registry, with USPS mail being superior to email. Given the low cost and time commitment for email recruitment [8], researchers using registries should leverage the use of both mail and email pre-notifications for online survey research in COPD.

Co-creating the recruitment message with patients with COPD was a novel addition to this study, probably contributing to enrolment success. Researchers aiming to use mail and email pre-notifications to recruit members of this patient population should not haphazardly develop a message and use these modalities; 
rather, they should consider the content of the message and conduct formative evaluations to assess its relevance and salience with intended audiences.

Participants passively recruited through social media had a greater completion rate than participants actively recruited from the research registry. Social media participants were considerably more diverse with regards to socio-demographics and living uninsured with more severe respiratory symptoms, when compared to research registry participants. Given that the research registry participants were two decades older, on average, the 20-min length of the survey could have contributed to the lower completion rate [11]. Patients with COPD who are dissatisfied with their healthcare experience often turn to online media to learn about their condition and gain support [13]. Social media participants may have treated this survey as a proactive opportunity to learn and contribute to their respiratory health. Research is needed to understand how recruitment messages can also serve as healthcare promotion tools.

\section{Samantha R. Paige ${ }^{1}$ and Janice L. Krieger ${ }^{1,2,3}$}

${ }^{1}$ STEM Translational Communication Center, University of Florida, Gainesville, FL, USA. ${ }^{2}$ Clinical and Translational Sciences Recruitment Center, University of Florida, Gainesville, FL, USA. ${ }^{3}$ Dept of Health Outcomes and Biomedical Informatics, College of Medicine, University of Florida, Gainesville, FL, USA.

Correspondence: Samantha R. Paige, STEM Translational Communication Center, University of Florida, PO Box 118400, Gainesville FL 32611, USA. E-mail: paigesr190@ufl.edu

Received: Sept 192018 | Accepted after revision: Feb 242019

Conflict of interest: None declared.

Support statement: Research reported in this publication was supported by the National Heart, Lung, and Blood Institute of the National Institutes of Health (NIH) under award numbers F31HL132463 and F32HL143938; and the NIH/NCATS Clinical and Translational Science Award to the University of Florida (grant number ULITR000064). Funding information for this article has been deposited with the Crossref Funder Registry.

\section{References}

1 Goldstein RS, O’Hoski S. Telemedicine in COPD: time to pause. Chest 2014; 145: 945-949.

2 Stellefson M, Paige SR, Alber JM, et al. COPD360social online community: a social media review. Health Promot Pract 2018; 19: 489-491.

3 PCORnet PPRN Consortium, Daughterty SE, Wahba S, et al. Patient-powered research networks: building capacity for conducting patient-centered clinical outcomes research. J Am Med Inform Assoc 2014; 21: 583-586.

4 Stellefson M, Alber J, Paige SR, et al. Evaluating comparative effectiveness research priorities for care coordination in chronic obstructive pulmonary disease: a community-based eDelphi study. JMIR Res Protocol 2015; 4: e103.

5 Jonsdottir H, Ingadottir TS. Reluctance of patients with chronic obstructive pulmonary disease in its early stages and their families to participate in a partnership-based self-management trial: a search for an explanation. Chron Respir Dis 2018; 15: 315-322.

6 Edwards P. Questionnaires in clinical trials: guidelines for optimal design and administration. Trials 2010; $11: 2$.

7 National Institutes of Health. COPD National Action Plan. www.nhlbi.nih.gov/sites/default/files/media/docs/ COPD\%20National\%20Action\%20Plan\%20508_0.pdf Date last updated: May 22, 2017. Date last accessed: January $25,2019$.

8 Christensen T, Riis AH, Hatch E, et al. Costs and efficiency of online and offline recruitment methods: a web-based cohort study. J Med Internet Res 2017; 19: e58.

9 Fan W, Yan Z. Factors affecting response rates of the web survey: a systematic review. Comp Human Behav 2010; 26: $132-139$

10 Bauman A, Phongsavan P, Cowle A, et al. Maximising follow-up participation rates in a large scale 45 and up study in Australia. Emerg Themes Epidemiol 2016; 13: 6.

11 Beebe TJ, Rey E, Ziegenfuss JY, et al. Shortening a survey and using alternative forms of prenotification: Impact on response rate and quality. BMC Med Res Method 2010; 10: 50.

12 Koitsalu M, Eklund M, Adolfsson J, et al. Effects of pre-notification, invitation length, questionnaire length and reminder on participation rate: A quasi-randomised controlled trial. BMC Med Res Method 2018; 18: 3.

13 Martinez $\mathrm{CH}$, St Jean BL, Plauschinat CA, et al. Internet access and use by COPD patients in the National Emphysema/COPD Association Survey. BMC Pulm Med 2014; 14: 66.

14 Flood-Grady E, Paige SR, Karimipour N, et al. A content analysis of clinical and translational science award (CTSA) strategies for communicating about clinical research participation online. J Clin Transl Sci 2017; 1: 340-351.

15 National Heart, Lung, and Blood Institute. Chronic Obstructive Pulmonary Disease (COPD). www.nhlbi.nih.gov/ health-topics/copd Date last updated: 2018. Date last accessed: January 10, 2019. 